\title{
Correction to: Nucleus replacement could get a new chance with annulus closure
}

\author{
Laura Zengerle $^{1} \cdot$ Anne Köhler $^{1} \cdot$ Elisabeth Debout ${ }^{1} \cdot$ Carsten Hackenbroch $^{2} \cdot$ Hans-Joachim Wilke $^{1}(\mathbb{0}$
}

Published online: 27 May 2020

(c) Springer-Verlag GmbH Germany, part of Springer Nature 2020

\section{Correction to: European Spine Journal https://doi.org/10.1007/s00586-020-06419-2}

Unfortunately, Fig. 7 and last paragraph of the result section have been incorrectly published. The complete corrected Fig. 7 and last paragraph of the results part (IDP measurements) have been as follows.

The IDP measurements during the flexibility tests showed a similar tendency (Fig. 7). The box-cut defect led to a decrease in the IDP, except for extension and left AR (Fig. 7). Accordingly to the findings in ROM and DH, after the prolapse and removal of the nucleus material, IDP decreased in all motion directions (Fig. 7). Only in flexion, a slight increase was measured. The implantation of the native collagen-type-I nucleus implant and annulus closure device increased IDP again, so that the initial values of the intact specimens have been reached in all motion directions. After the long-term cyclic loading with 100,000 load cycles,

The original article can be found online at https://doi.org/10.1007/ s00586-020-06419-2.

Hans-Joachim Wilke

hans-joachim.wilke@uni-ulm.de

Laura Zengerle

laura.zengerle@uni-ulm.de

Anne Köhler

annekoehler2@gmx.de

Elisabeth Debout

elisabeth.debout@mail.de

Carsten Hackenbroch

cmhacki@gmx.de

1 Institute of Orthopaedic Research and Biomechanics,

Trauma Research Center Ulm, Ulm University, Ulm,

Germany

2 Department of Radiology, German Armed Forces Hospital of Ulm, Ulm, Germany
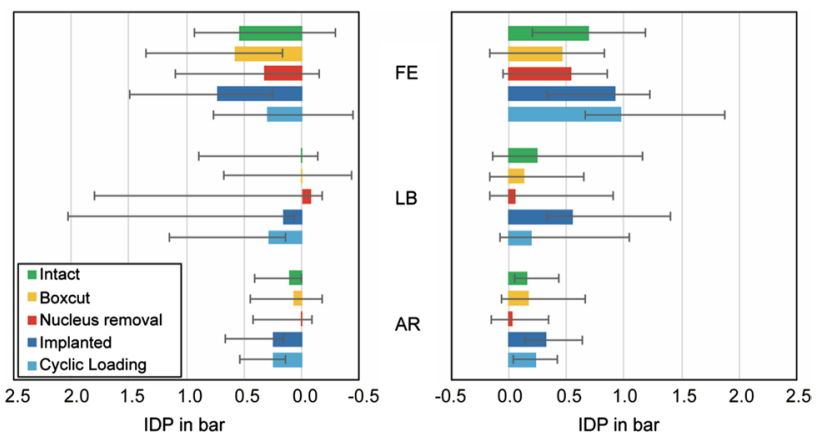

Fig. 7 Median and ranges for IDP in all motion planes FE (+ : flexion, - extension), LB (+ : left lateral bending, - right lateral bending) and $\mathrm{AR}$ (+ : left axial rotation, - right axial rotation) for pure moments of $\pm 7.5 \mathrm{Nm}$ assessed with the spine tester

IDP did change, but not following the same pattern for different loading planes as it could be observed for the ROM (Figs. 6, 7).

Publisher's Note Springer Nature remains neutral with regard to jurisdictional claims in published maps and institutional affiliations. 